\title{
NOTA
}

\section{DETECÇÃO DE Azospirillum amazonense EM RAÍZES E RIZOSFERA DE ORCHIDACEAE E DE OUTRAS FAMÍLIAS VEGETAIS ${ }^{(1)}$}

\author{
A. LANGE ${ }^{(2)} \&$ F. M. S. MOREIRA ${ }^{(3)}$
}

\begin{abstract}
RESUMO
Azospiril lum amazonenseé uma bactéria fixadora de $\mathrm{N}_{2}$ atmosférico de ampla ocorrência, principalmente em associações radiculares com gramíneas e palmeiras. Para verificar sua presença em outras espécies vegetaís, ainda não estudadas, e a eficiência de meios para sua detecção, foram testados os meios Fam e L GI para contagens em solo rizosférico ou em culturas de enriquecimento com solo rizosférico, ecto e endorrizosfera. A. amazonense foi detectada no solo rizosférico, ecto e endorrizosfera de várias espécies de monocotiledôneas, incluindo Orchidaceae e dicotiledôneas, sendo o meio Fam mais eficiente para sua detecção
\end{abstract}

Termos de indexação: diazotróficos, ecologia microbiana, fixação de nitrogênio.

\section{SUMMARY: DETECTION OF Azospirillum amazonense IN ROOTS AND RHIZOSPHERE OF ORCHIDACEAE AND OTHER PLANT FAMILIES}

Azospirillum amazonense is a widespread $\mathrm{N}_{2}$ fixing bacterium, occurring mainly in association with grasses and pal $\mathrm{m}$ trees roots. Aiming to study its occurrence in species of other families not yet studied and the efficiency of media. Fam and LGI for its detection, thesewereused for rhizospheresoil counting or for enrichment cultures of rhizosphere soil, ecto and endorhizosphere. A. amazonense was detected in rhizosphere soil, ecto and endorhizosphere of many species bel onging to monocotyledons, including Orchidaceae and dicotyledons with. Fam medium being the most efficient for its detection.

Index terms: diazotrophs, microbial ecology, nitrogen fixation.

\footnotetext{
(1) Recebido para publicação em julho de 2000 e aprovado em dezembro de 2001.

(2) Mestrando em Solos e Nutrição de Plantas, Universidade Federal de Lavras - UFLA. Caixa Postal 37, CEP 37200-000 Lavras (MG). Bolsista da FAPEMIG. E-mail: paranalange@hotmail.com

(3) Professor do Departamento de Ciência do Solo, UFLA. Bolsista do CNPq. E-mail: fmoreira@ufla.br
} 


\section{INTRODUÇÃO}

Bactérias da espécie Azospirillum amazonense são capazes de fixar $\mathrm{N}_{2}$ atmosférico em associação com diferentes espécies de plantas e são encontradas tanto na ectorrizosfera como na endorrizosfera de gramíneas, ci peráceas, palmeiras ealgumas espécies de outras famílias em diversos ecossistemas na Amazônia (Magal hães, 1983; Magal hães et al ., 1983; Magalhães \& Döbereiner, 1984), assim comoem gramíneas graníferas nosudeste brasilei ro (Bal dani, 1984).

A primeira estirpe isolada de $A$. amazonense (15M1) (Magalhães, 1981) foi obtida mediante cultivos de enriquecimento de raízes de Brachiaria brizantha, coletada na Amazônia, em meio NFb de Döbereiner (1980), modificado por meio da adição de $0,5 \mathrm{~g}$ de manitol e 0,5 g de sacarose. Nesse trabalho, foi verificada a capacidade desta estirpe em crescer em sacarose como única fonte de carbono, ao contrário das outras espécies então conhecidas de Azospirillum (A. lipoferum e A. brasilense).

Assim, esta característica e a comprovação do melhor crescimento em val ores de pH entre 5,0 e 6,0 levaram aoaprimoramento do meio deenriquecimento (Magalhães, 1983), usado para avaliar a distribuição ecológica da espécie (Magal hães \& Döbereiner, 1984). $\mathrm{O}$ isolamento deorganismo similar por pesquisadores do PNPBS/EMBRAPA levou à publicação conjunta do trabalhodeproposiçãoda espédie(Magal hães et al., 1983).

Neste trabalho, o meio de isolamento descrito (LGI) foi o utilizado por Souto (1982) que constava de uma nova modificação do LG já modificado por Magalhães et al. (1979) e que apresentava certa similaridade com o meio de Magalhães (1983) e Magalhães \& Döbereiner (1984), porém sem adição de vários micronutrientes e vitaminas. Com a supressão de micronutrientes essenciais, em estudos posteriores sobre A. amazonense, que utilizaram o meio LGI , foram encontrados, geralmente, números inferiores aos das espécies A. li poferum eA. brasilense (Baldani, 1984; Baldani et al., 1999) e ocorrência regional mais restrita, ao contrário do observado por Magal hães (1983) e Magalhães \& Döbereiner (1984). Recentemente, o LGI foi modificado por meio da adição de vitaminas e substituição de $\mathrm{FeCl}_{3}$ por FeEDTA (Döbereiner et al., 1995).

O objetivo destetrabalho foi verificar a ocorrência de Azospi rillum amazonense em amostras de solo e de raízes de diferentes famílias vegetais, incluindo Orchidaceae, comparando a eficiência dos meios LGI modificado e de Magal hães (1983), aqui denominado Fam, para detecção da espécie.

\section{MATERIAL E MÉTODOS}

Foram realizados no Setor de Microbiologia do Solo do DCS/UFLA dois experimentos, com vistas em pesquisar a ocorrência de $A$. amazonense em amostras de solo e de raízes de diversas espécies vegetais no campo ou em vasos (Orchidaceae), coletadas no campus da UFLA, de outubro de 1999 a maio de 2000. Com exceção das Orchidaceae, cujas amostras foram escolhidas em vasos, em todas as espécies foram coletadas al eatoriamente cinco subamostras (de solo ou de raízes) no campo para formar uma amostra composta. Em mata nativa, raízes de várias espécies foram coletadas e misturadas.

No primeiro experimento, efetuou-se a contagem de A. amazonensepelo método das diluições decimais sucessivas (totalizando cinco diluições com três repetições cada) de solo rizosférico de 13 espécies vegetais e de mistura de espécies de mata nativa em solução aquosa de $\mathrm{NaCl}$ a 0,55 \% ( $1^{\text {a }}$ diluição: $10 \mathrm{~g}$ desolo/90 mL desoluçãosalina). Alíquotas $(0,1 \mathrm{~mL})$ de cada diluição foram transferidas para os meios Fam e LGI e as culturas incubadas a $28^{\circ} \mathrm{C}$. O crescimento de $A$. amazonense nas culturas foi considerado positivo após formação de película próxima à superfície dos meios, típica do crescimento desta espécie, e observação das culturas ao microscópio. As contagens foram realizadas pelo método do Número Mais Provável (NMP), utilizando a tabela de Cochran (1950). As espécies estudadas foram: Lycopersicon esculentum, Coel ogyne massangeana, Paspalum notatum, Panicum sp., Bambusa vulgaris, Zea mays, Coffea arabica, Triticum aestivum, Brachiaria decumbens, Pennisetum purpureum, Pinus sp., Eucalyptus grandis, e Saccharum officinarum.

Nosegundoexperimento, pesquisou-sea ocorrência de $A$. amazonense no substrato de crescimento ou solo rizosférico (situado a $5 \mathrm{~mm}$ da superfície radicular), na ectorrizosfera e na endorrizosfera de 12 diferentes espécies vegetais, de 10 espécies de orquídeas e de mistura de diversas espécies col etadas em mata nativa. Para isto, inocularam-seem meios Fam e LGI pequenas amostras de solo rizosférico, pedaços de raízes $( \pm 0,5 \mathrm{~cm})$, que foram apenas sacudidas para eliminação dos grânulos de solo (ecto + endorrizosfera), ou pedaços de raízes desinfestadas superficial mente por imersão durante 10 min em solução de Cloramina T (1\%) e lavadas em água estéril seis vezes, para remoção do produto químico (endorrizosfera). Foram feitas cinco repetições por tipo de amostra. As espécies estudadas foram Brassica ol eraceae, Brachiaria decumbens, Pennisetum purpureum, Eucalyptus grandis, Zea mays, Saccharum officinarum, Elaeis guineensis, Panicum sp., Paspalum notatum, Coffea arabica, Pinus sp., Bambusa vul garis edeOrchidaceae: Laelia purpurata, Oncidium varicosum, Miltonia flavecens, Dendrobium moschatum, Vanda tricol or, Laelia flava brasil, Dendrobium fimbriatum, Epidendrum sp., Dendrobium nobilis e Coelogyne lawrenceana. A comprovação da presença de A. amazonense nas amostras foi feita como no experimento anterior.

Os meios testados apresentaram a seguinte 
composição:

Fam - sacarose, $5 \mathrm{~g} ; \mathrm{KH}_{2} \mathrm{PO}_{4}, 0,12 \mathrm{~g} ; \mathrm{K}_{2} \mathrm{HPO}_{4}$, $0,03 \mathrm{~g} ; \mathrm{MgSO}_{4} \cdot 7 \mathrm{H}_{2} \mathrm{O}, 0,2 \mathrm{~g} ; \mathrm{CaCl}_{2}, 0,02 \mathrm{~g}$; FeEDTA, 0,066 g; $\mathrm{NaCl}, 0,1 \mathrm{~g} ; \mathrm{NaMoO}_{4} \cdot 2 \mathrm{H}_{2} \mathrm{O}$, $0,002 \mathrm{~g} ; \mathrm{MnSO}_{4}, 0,00235 \mathrm{~g} ; \mathrm{H}_{3} \mathrm{BO}_{3}, 0,0028 \mathrm{~g}$; $\mathrm{CuSO}_{4} .5 \mathrm{H}_{2} \mathrm{O}, 8 \times 10^{-5} \mathrm{~g} ; \mathrm{ZnSO}_{4} .7 \mathrm{H}_{2} \mathrm{O}, 0,00024 \mathrm{~g}$; biotina, 0,1 mg; piridoxina $\mathrm{HCl} \mathrm{0,2} \mathrm{mg;} \mathrm{ágar}$ $1,75 \mathrm{~g} ; \mathrm{pH} 6,0$, água q.s.p $1.000 \mathrm{~mL}$.

LGI - composição original: sacarose, $5 \mathrm{~g} ; \mathrm{KH}_{2} \mathrm{PO}_{4}$, $0,6 \mathrm{~g} ; \mathrm{K}_{2} \mathrm{HPO}_{4}, 0,2 \mathrm{~g} ; \mathrm{MgSO}_{4} .7 \mathrm{H}_{2} \mathrm{O}, 0,2 \mathrm{~g} ; \mathrm{CaCl}_{2}$, $0,02 \mathrm{~g} ; \mathrm{Na}_{2} \mathrm{MoO}_{4} .2 \mathrm{H}_{2} \mathrm{O}, 0,002 \mathrm{~g} ; \mathrm{FeCl}_{3}, 0,01 \mathrm{~g}$; agar 1,75 g; pH 6,0, água q.s.p. $1.000 \mathrm{~mL}$. Azul de bromotimol sol. 0,5\% em 0,2 N KOH (5 mL) também foi adicionado ao meio. O meio Döbereiner et al. (1995) modificado com $4 \mathrm{~mL}$ FeEDTA sol $1,64 \%(0,066 \mathrm{~g}$ FeEDTA) foi utilizado, substituindo o $\mathrm{FeCl}_{3}$ eadição de $0,1 \mathrm{mg}$ de biotina e 0,2 mg de $\mathrm{HCl}$-piridoxina por litro.

\section{RESULTADOS E DISCUSSÃO}

No primeiro experimento, Azospirillum amazonense foi detectada no solo rizosférico de oito das 13 espécies pesquisadas, em números de até 3,3 $\times 10^{5}$ (Quadro 1). No segundo experimento, foi detectada tanto na rizosfera como na ecto + endorrizosfera e endorrizosfera de 17 das 22 espécies vegetais estudadas, incluindo a maioria das Orchidaceae, sendo mais freqüente no sol o e na ecto + endorrizosfera, com percentagens de ocorrência quase semel hantes entre estes tipos de amostras (Quadro 2). A percentagem de tubos positivos quanto à presença destes organismos variou de 0 a $100 \%$. Esta grande variação pode ser devida à distribui ção al eatória deste organismo nas amostras já comprovada para outras espécies (Rovira et al., 1974; Olivares et al., 1995; Bellone et al., 1995).

Além disso, o número relativamente baixo (5) de amostras analisadas para cada espécie contribuiu também para o aumento da variabilidade. Provavelmente por isso, em algumas espécies (no primeiro experimento: Brachiaria decumbens, Pennisetum purpureum, Pinus sp., Eucalyptus grandis, e Saccharum officinarum; no segundo experimento: Pinus sp., Bambusa vulgaris, Coffea arabica e Coel ogynel awrenceana), não foi detectada a presença de $A$. amazonense $A$ ausência de $A$. amazonense em mata nativa foi verificada nos dois experimentos e corrobora as observações de Magalhães \& Döbereiner (1984) que também não encontraram esta espécie na floresta amazônica.

Números mais el evados de A. amazonenseforam obtidos em sol o rizosférico de sete das nove espécies estudadas pelo meio Fam (Quadro 1). Em vários tipos de amostras (14), A. amazonensefoi detectada apenas pelo meio Fam e em número menor (5) apenas pelo meio LGI (Quadro 2). Considerando o número de amostras positivas em relação ao número total de amostras col etadas (Quadro 2 ), o meio Fam detectou $A$. amazonenseem freqüências maiores que o meio LGI, excetuando apenas amostras da ecto + endorrizosfera de plantas não pertencentes às orquidáceas. Portanto, a presença dos micronutrientes Mn, B, Cu eZn, essenciais ao crescimento bacteriano (Madigan et al., 1996), deve estimular o crescimento destes organismos no meio Fam, pois estes nem sempre podem estar presentes nas amostras de solo e raízes amostradas, em concentrações adequadas, principalmente quando estes são diluídos para contagem.

Este trabalho mostra, pela primeira vez, a ocor-

Quadro 1. Densidade de A. amazonense (Número Mais Provável) no solo rizosférico de nove espécies vegetais, calculada pelo método das diluições sucessi vas inoculadas nos mei os F am e L GI, utilizando a tabela de Cochran (1950)

$\begin{array}{lll}\text { Espécie vegetal } & \text { LGI } & \text { Fam }\end{array}$

Trigo (Triticum aestivum)(1)

Tomate (Lycopersicon esculentum)(2)

Orquídea (Coelogyne massangeana)(2)

Grama batatais irrigada(5) (Paspalum notatum)(2)

Grama batatais não irrigada(5) (Paspalum notatum)(2)

Capim-capituba (Panicum sp)(3)

Bambu (Bambusa vulgaris)(3)

Milho (Zea mays)(4)

Café (Coffea arabica)(4)
No de bactérias/g solo

$\begin{array}{lr}0 & 3,0.10^{2} \\ \rightarrow 1,2 \cdot 10^{3} & 2,0.10^{2} \\ 1,4.10^{4} & \rightarrow 2,3 \cdot 10^{4} \\ 6,3 \cdot 10^{4} & \rightarrow 1,3 \cdot 10^{5} \\ 1,9.10^{2} & \rightarrow 5,6.10^{2} \\ 1,6.10^{4} & \rightarrow 3,3.10^{5} \\ 0 & \rightarrow 9,8 \\ \rightarrow 1,2.10^{3} & 5,1.10^{2} \\ 1,9.10^{2} & \rightarrow 3,1.10^{2}\end{array}$

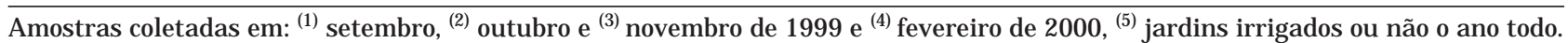


Quadro 2. Ocorrência de A. amazonense em solo rizosférico, ectotendorrizosfera( ${ }^{(1)}$ e endorrizosfera ${ }^{(2)}$ de várias espécies vegetais e de Orchidaceae em culturas de enriqueci mento de amostras ${ }^{(3)} \mathrm{em}$ meios Fam e LGI (repetições positivas em um total de cinco por espécie vegetal)

\begin{tabular}{|c|c|c|c|c|c|c|}
\hline \multirow{2}{*}{ Espécie vegetal } & \multicolumn{2}{|c|}{ Solo/substrato } & \multicolumn{2}{|c|}{ Ecto + endo rizosfera } & \multicolumn{2}{|c|}{ Endorrizosfera } \\
\hline & LGI & Fam & LGI & Fam & LGI & Fam \\
\hline Couve (Brassica oleraceae) & 3 & 2 & 4 & 0 & 1 & 0 \\
\hline Brachiaria (Brachiaria decumbens) & 1 & 0 & 0 & 1 & 0 & 0 \\
\hline Napier (Pennisetum purpureum) & 5 & 4 & 4 & 3 & 4 & 5 \\
\hline Eucalipto (Eucalyptus grandis) & 0 & 0 & 0 & 1 & 0 & 1 \\
\hline Milho (Zea mays) & 0 & 2 & 3 & 2 & 4 & 1 \\
\hline Cana-de-açúcar (Saccharum officinarum) & 4 & 1 & 2 & 1 & 0 & 0 \\
\hline Palmeira (Elaeis guineensis) & 0 & 1 & 0 & 0 & 0 & 0 \\
\hline Capim-capituba (Panicum sp) & 4 & 5 & 5 & 5 & 0 & 4 \\
\hline Grama batatais irrigada(4) (Paspalum notatum) & 0 & 3 & 2 & 4 & 0 & 0 \\
\hline Laelia purpurata & 2 & 1 & 2 & 0 & 0 & 0 \\
\hline Oncidium vari cosum & 1 & 3 & 4 & 3 & 1 & 2 \\
\hline Miltonia flavecens & 0 & 4 & 0 & 0 & 0 & 0 \\
\hline Dendrobium moschatum & 1 & 0 & 0 & 0 & 0 & 0 \\
\hline Vanda tricolor & 0 & 0 & 0 & 2 & 5 & 5 \\
\hline Laelia flava Brasil & 0 & 2 & 0 & 0 & 0 & 0 \\
\hline Dendrobium fimbriatum & 0 & 0 & 0 & 3 & 1 & 2 \\
\hline Epidendrum & 0 & 1 & 0 & 0 & 0 & 0 \\
\hline Dendrobium nobili & 0 & 0 & 0 & 2 & 0 & 1 \\
\hline № de amostras positivas/ total amostras & $21 / 90$ & $29 / 90$ & $26 / 90$ & $27 / 90$ & $16 / 90$ & $21 / 90$ \\
\hline Percentuais & 23 & 32 & 29 & 30 & 18 & 23 \\
\hline
\end{tabular}

(1) Partículas de solo el iminadas das raízes apenas por agitação. ${ }^{(2)}$ Raízes desinfestadas superficialmente para detecção apenas dos microrganismos que habitam os tecidos radiculares internos. (3) Amostras col etadas em março de $2000 .{ }^{(4)}$ I rrigada 0 ano todo.

rência defixadores de $\mathrm{N}_{2}$ no substrato decrescimento e na ecto e endorrizosfera de várias espécies de orquídeas eem números elevados. A eficiência destas espécies em utilizar nutrientes de substratos pobres ou de partículas em suspensão no ar é geralmente atribuída à sua simbiose com fungos micorrízicos (Smith \& Read, 1997). Assim, a comprovação da presença de fixadores de $\mathrm{N}_{2}$ indica queestes também podem estar contribuindo significativamente com nitrogênio para a nutrição destas espécies.

\section{CONCLUSÕES}

1. Azospirillum amazonensepode ser encontrada em diversas espécies de monocotiledôneas, induindo Orchidaceae, além de dicotiledôneas herbáceas, arbustivas e arbóreas.

2. O mei o Fam foi mais eficiente para detecção de Azospi rillum amazonense em relação ao meio LGI .

\section{LITE RATURA CITADA}

BALDANI, J.I. Ocorrência e caracterização de Azospirilum amazonense em comparação com as outras espécies deste gênero em raízes de milho, sorgo e arroz. Seropédica, Universidade Federal Rural do Rio deJ aneiro, 1984. 110p. (Tese de Mestrado)
BALDANI, J .I .;AZEVEDO, M.S.; REIS, V.M.;TEIXEIRA, K.R.S.; OLIVARES, F.L.; GOI, S.R.; BALDANI, V.L.D. \& DÖBEREINER, J. Fixação biológica de nitrogênio em gramíneas: Avanços e aplicações. In: SIQUEIRA, J.O. et al., eds. Inter-relação fertilidade, biologia do sol o e nutrição de plantas. Lavras, Universidade Federal de Lavras, Sociedade Brasileira de Ciência do Solo, 1999, p.621-666.

BELLONE, C.H.; BELLONE, S.D.V.C.; PEDRAZA, R.O. \& MONZÓN, M.A. Cell colonization of sugar cane roots by Acetobacter diazotrophicus. In: INTERNATIONAL SYMPOSIUM ON SUSTAINABLE AGRICULTURE FOR THE TROPICS - The role of biological nitrogen fixation. Angra dos Reis, 1995. Programme and Abstracts. Angra dos Reis, 1995. p.204-205.

COCHRAN, W.G. Estimation of bacterial densities by means of the "most probable number", Biometrics, 6:105-116, 1950.

DÖBEREINER, J. Forage grasses and grain crops. In: BERGERSEN, F.J . ed. Methods for Evaluating Biological Nitrogen Fixation. New York, J ohn Wiley \& Sons, 1980. p.535-555.

DÖBEREINER, J.; BALDANI, V.L.D. \& BALDANI, J.I. Como isolar e identificar bactérias diazotróficas de plantas nãoleguminosas. Brasília, Empresa Brasileira de Pesquisa Agropecuária, 1995. 60p.

MADIGAN, M.T.; MARTINKO, J.M. \& PARKER, J . Brock Biology of Microorganisms. 8.ed. PrenticeHall, Upper SaddleRiver, 1996. 986p. 
MAGALHÃES, F.M.M. Nitrogen fixing bacteria isolated from diverse soils and grass roots in Amazônia. In: VOSE, P. \& RUSCHEL, A.P., eds. Associative $\mathrm{N}_{2}$-Fixation. New York, CRC Press, 1981. p.39-48.

MAGALHÃES, F.M.M. Caracterização e distribuição de uma nova espécie de bactéria fixadora de nitrogênio. Manaus, Instituto Nacional de Pesquisa do Amazonas/FUA, 1983. 89p. (Tese de Mestrado)

MAGALHÂES, F.M.M. \& DÖBEREINER, J. Ocorrência de Azospirillum amazonense em alguns ecossistemas da Amazônia. R. Microbiol., 15:246-252, 1984.

MAGALHÃES, F.M.M.; PATRIQUIN, D. \& DÖBEREINER, J. Infection of field grown maize with Azospirillum spp. R. Bras. Biol., 39:587-596, 1979.

MAGALHÃES, F.M.M.; BALDANI, I.I:; SOUTO, S.M.; KUYKENDALL, J.R. \& DÖBEREINER, J. A new acidtolerant Azospirillum species. An. Acad. Bras. Ci., 55:417430, 1983.
OLIVARES, F.L.; REIS, F.B.; REIS, V.M.; BALDANI, V.L.D.; BALDANI, J I. \& DÖBEREINER, J . Infection of sugarcane roots by the endophytic diazotrophs Herbaspirillum seropedicaeand $\mathrm{H}$. rubrisubal bicans. In: INTERNATIONAL SYMPOSIUM ON SUSTAINABLE AGRICULTURE FOR THE TROPICS - The role of biological nitrogen fixation. Angra dos Reis, 1995. Programme and Abstracts. Angra dos reis, 1995. p.65-66.

ROVIRA, A D.; NEWMAN, E.I.;BOWEN, H.J . \& CAMPBELL, R. Quantitative assessment of the rizoplane microflora by direct microscopy. Soil. Biol. Biochem., 6:211-216, 1974.

SMITH, S.E. \& READ, D.J . Mycorrhizal symbiosis 2.ed. San Diego, Academic Press, 1997. 605p.

SOUTO, S.M. Variação estacional da fixação de $\mathrm{N}_{2}$ e denitrificação em gramíneas forrageiras tropicais. Seropédica, Universidade Federal Rural do Rio deJ aneiro, 1982. 268p. (Tese de Doutorado) 
A. LANGE \& F.M.S. MOREIRA 